\title{
Policy Implementation Performance and Political Trust
}

\author{
Zhengyang Meng \\ International Business School \\ Yunnan University of Finance and Economics \\ Kunming, China \\ 247096657@qq.com \\ Dongping $\mathrm{Yu}^{*}$ \\ International Business School \\ Yunnan University of Finance and Economics \\ Kunming, China \\ 386818100@qq.com
}

\author{
Jingfei Wang \\ International Business School \\ Yunnan University of Finance and Economics \\ Kunming, China \\ 864639017@qq.com
}

\author{
Sai Zhao \\ International Business School \\ Yunnan University of Finance and Economics \\ Kunming, China \\ 739457672@qq.com
}

\begin{abstract}
Political trust is the embodiment of a country's ruling level. From the micro psychological perspective of the audience's political trust in policy implementation, the research systematically puts forward and empirically verifies the hypothesis of the relationship between policy implementation performance and political trust. The results show that: (1) policy implementation performance has a significant positive impact on political trust. Among them, compared with government trust and official trust, policy implementation performance has the most powerful positive role in promoting policy trust; so do administrative performance, social performance and economic performance.(2)policy implementation performance on government trust and official trust is not obvious, mainly because there are other more complex regulatory mechanisms.
\end{abstract}

Keywords: political trust, policy implementation performance, policy trust

\section{INTRODUCTION}

Since the 1960s, political trust has gradually been favored by American scholars, and a large number of political trust research results have emerged. By the 1990s, Chinese scholars gradually paid attention to the issue of political trust [1]. Political trust is an important part of political culture, and at the same time it is the embodiment of the public's recognition of the country's ability to govern. At the important stage of the great rejuvenation of the Chinese nation, under the theoretical guidance of Xi Jinping's new era of socialism with Chinese characteristics, political trust is an external manifestation of road self-confidence, institutional self-confidence, theoretical self-confidence, and cultural self-confidence. Only the public has a high degree of political trust in the country, and four confidences can have a solid guarantee.

As a macroscopic social capital, political trust may play a greater role in promoting political economy than social capital, economic capital and human capital. Therefore, the study of

*Corresponding author political trust is of great value. The so-called political trust refers to the trust and support of the rights holders in the public power structure and their powers in a political system, or the belief that the government or the political system will operate to be consistent with their expectations or confidence [2]. Scholars have divided the dimensions of political trust at different levels based on different research purposes and research perspectives. For example, Blind [3] believes that political trust has two levels: macro (that is trust in policy organization) and micro (that is trust in government officials or political leaders); Xiao Tangbiao and Wang Xin [4] think political trust from a broad perspective Including trust in the political community, trust in the general government, and trust in the political elite; Wang [5] believes that political trust includes interpersonal trust (ie,public trust in government actors, government administrators) and organizational trust. (ie,public trust in political systems and government agencies).

The main theory of the theory of action theory is that "policy implementation is an activity that puts a policy into practice. Among many activities, interpretation, organization and implementation are the most important [6]. The so-called explanation is to transform the content of the policy. A directive acceptable to the public. The so-called organization refers to the establishment of a policy enforcement agency to formulate implementation methods to achieve policy objectives.

This paper mainly analyzes the influence of the efficiency of policy execution on the political trust of the public from the perspective of government policy implementation efficiency and policy implementation behavior theory.

\section{LITERATURE REVIEW AND PROBLEM HYPOTHESIS}

\section{A. Policy Implementation and Political Trust}

The so-called policy implementation is that after the policy plan is adopted, the policy implementer uses a certain organizational form, uses various policy resources, and 
translates the content of the policy concept form into a realistic effect through actions such as interpretation, implementation, service, and propaganda. The process of the goal [7]. Whether the policy can effectively play its role depends largely on the efficiency of policy implementation. The main body of policy implementation is government officials, and the policy audience is all relevant personnel. Political trust depends on the ability of the government to provide people with good policies and good ways, and whether people feel good about government officials [8]. Therefore, this can reflect to a certain extent that the government's policy implementation efficiency will have an impact on the public's political trust in the government. Based on this, the following assumptions are made:

H1(a,b,c):Policy implementation performance (including administrative performance, social performance, economic performance) has a significant positive impact on the level of government trust in political trust.

H2(a,b,c):Policy implementation performance (including administrative performance, social performance, economic performance) has a significant positive impact on the level of policy trust in political trust.

H3(a,b,c):Policy implementation performance (including administrative performance, social performance, economic performance) has a significant positive impact on the trust level of officials with political trust.

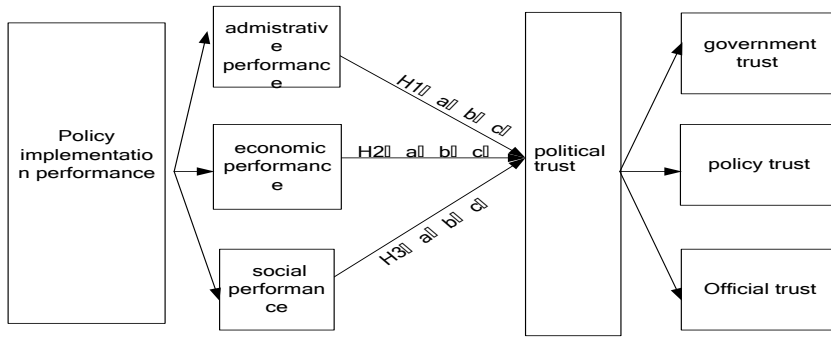

Fig. 1 The concept model and hypotheses of this study.

\section{RESEARCH DESIGN}

\section{A. Data and Samples}

Since data such as policy implementation efficiency and political trust cannot be obtained from public information, this paper uses large-scale enterprise questionnaires to collect data and empirical analysis. In order to ensure the quality of the sample and the data is true and effective, the influence of interference factors should be eliminated as much as possible. In order to ensure the quality of the data, this study first made a small sample of data collection and pre-test. After the small sample factor analysis, the questionnaire was reasonably finetuned, and then a large-scale questionnaire was issued. Questionnaires were distributed mainly on the ground, and some were conducted by mail and telephone surveys for a total of 6 months. Finally, 400 questionnaires were distributed and 245 questionnaires were returned, with a recovery rate of $61 \%$. Among them, 162 valid questionnaires, the effective rate was $66.12 \%$. The reason for the invalidity of the questionnaire was mainly because the questionnaire filling rate of the subjects was less than $95 \%$. From the basic characteristics of the sample surveyed, 86 males and 76 females, accounting for $53.1 \%$ and
$46.9 \%$, respectively; the majority of the subjects were in the ages of 21-30 and 31-40. , accounting for 51.6\% and $38.5 \%$ respectively; the educational background of the sample was mainly concentrated in undergraduate, postgraduate and above, accounting for $54.7 \%$ and $34.2 \%$ respectively; the sample middle and middle managers, middle managers and grassroots managers The ratios were $17.4 \%, 35.4 \%$ and $47.2 \%$, respectively. These features of the sample were in accordance with the sample requirements of this study.

\section{B. Variables and Measurements}

Most of the items used in this research questionnaire are from more mature measurement scales abroad. In order to ensure the quality of the scale, the translation work is completed by a number of professional researchers in the field of management who have overseas study and work experience. In the pre-study, the expressions of some items were revised and adjusted through interviews and communication, so that their expressions are more in line with the actual situation and understanding of the subjects.

\section{1) EXPLANATORY VARIABLES}

The explanatory variables involved in this paper are policy performance, which refers to the effectiveness and value of policy implementation, mainly reflected in administrative performance (including the realization of the intended objectives, the continuity of implementation, the integrity of relevant supporting policies, internal and external monitoring mechanisms). (Completeness, etc.), economic performance (including tax reductions, settlement of financing dilemmas, reduction of barriers, promotion of technological innovation, etc.) and social performance (including overall social effects, employment driving, social stability promotion) Situation, etc.) Mainly referring to the research of Zhu Zhuangrui and Lu Ping (2015)[9], the paper designed 6 items of administrative performance, 4 items of social performance, and 6 items of economic performance to measure policy implementation performance.

\section{2) Explained Variable}

The explanatory variable involved in this paper is political trust, which refers to the extent to which the general public recognizes a government (or local) government and its behavior [10], including trust in government agencies (ie, government trust), and public provision to the government. The trust of the service (ie, policy trust) and the trust of government officials (ie, official trust). Mainly with reference to the literature research of Xiao Tang Dart and Wang Xin [11], the government has designed five items of trust, six items of policy trust, and five items of officials trust to measure political trust.

\section{3) CONTROL VARIABLE}

Taking into account the influence of variables such as gender [12], age [13], education level [14], position [15] on policy implementation and political trust, this paper measures the above variables as control variables. The content of this questionnaire mainly includes two parts: The first part is the survey of the basic situation of enterprises and subjects, including the industry of the company, the nature of the company, the size of the company (number of employees, total assets, operating income), gender and age of the subjects. , 
education level, position in the company, etc. The second part is the specific measurement of the research variables in the enterprise practice, including the three dimensions of policy performance (administrative performance, economic performance and social performance) and three dimensions of political trust (including government trust, policy trust and official trust). The questionnaire uses the Likert seven-scale scoring method, requiring participants to " 1 . completely disagree, 2 . disagree, 3 basically disagree, 4. general, 5 . basic consent, 6. agree, 7. fully agree" Score the score in the evaluation. The number of employees of the company requires the respondents to fill in according to the actual situation of the company from "1. 0-10 people, 2.11-100 people, 3.101-300 people, 4.300 or more". The total assets of the company will be filled in accordance with "1.0-300 million yuan, 2.301-20 million yuan, 3.2001-100 million yuan, and more than 410 million yuan". The company's annual business income is filled in accordance with "1.0-100 million yuan, 2.101-5 million yuan, 3.501-20 million yuan, more than 420 million yuan".

\section{Reliability and Validity Test}

The Cronbachundefineds $\alpha$ coefficient is used to measure the consistency of the internal structure of the factors. The results showed that the Cronbachundefineds $\alpha$ coefficients of the three variables of political trust, emotional infection and executive performance were $0.940,0.837$ and0.931, respectively. The Cronbachundefineds $\alpha$ coefficients of the specific dimensions of the three measurement variables. This shows that the scale has sufficient reliability.

For factor analysis, the relevant data were first measured using the KMO test and the Bartlett sphere test. The results show that the KMO values of the three measures of performance and political trust are 0.925 and 0.909 , respectively, which are greater than 0.7 . The approximate probability of the approximate chi-square statistics of the Bartley sphere test is 0.000 , both less than 0.001 . Based on the above test results, the principal component analysis method was used to analyze the political trust, emotional infection, and performance extraction factors. A factor loading matrix is obtained using the orthogonal rotation method with Kaiser normalization. Among them, the three factors proposed after the rotation of political trust can explain $70.281 \%$ of the main variables, and the three factors proposed after the execution of performance rotation can explain $71.031 \%$ of the main variables.

Preliminary correlations between the variables were tested and the variables involved were included in the Pearson correlation coefficient matrix, resulting in the correlation of the variables shown in Table 1. It can be seen from Table 1 that the relationship between economic performance and government trust is not significant, and the relationship between administrative performance and social performance and government trust is significantly positively correlated, thus presuming the hypothesis $\mathrm{H} 1 \mathrm{c}(\mathrm{a}, \mathrm{b}, \mathrm{c})$ and verifying $\mathrm{H} 1 \mathrm{~b}, \mathrm{H} 1 \mathrm{c}$. The relationship between administrative performance, economic performance and social performance and policy trust is significantly positively correlated, thus preliminarily verifying $\mathrm{H} 2(\mathrm{a}, \mathrm{b}, \mathrm{c})$ : the relationship between social performance and official trust is not significant, and the relationship between administrative benefit and economic benefit is significantly positively correlated. Initially negated $\mathrm{H} 3 \mathrm{~b}(\mathrm{a}, \mathrm{b}, \mathrm{c})$ and verified $\mathrm{H} 3 \mathrm{a}(\mathrm{a}, \mathrm{b}, \mathrm{c}), \mathrm{H} 3 \mathrm{c}(\mathrm{a}, \mathrm{b}, \mathrm{c})$.

TABLE I The Variables' Correlation Analysis

\begin{tabular}{|c|c|c|c|c|c|c|c|c|c|c|}
\hline & (1)GendeI & r(2)Age & (3)Education & (4)Level & (5)Gove & t(6)Policy & $(7)$ & (8)Administra & e(9)Economic & (10) Social \\
\hline & & & & & trust & trust & Official & performance & performance & performance \\
\hline (1)Gender & 1 & & & & & & & & & \\
\hline (2)Age & $-0.233^{* * *}$ & 1 & & & & & & & & \\
\hline (3)Education & 0.006 & h $156^{* *}$ & 1 & & & & & & & \\
\hline (4)Level & $0.210^{* * *}$ & h $417^{* * *}$ & -0.018 & 1 & & & & & & \\
\hline $\begin{array}{l}\text { (5)Government } \\
\text { trust }\end{array}$ & 0.036 & $-0.139^{*}$ & -0.092 & 0.060 & 1 & & & & & \\
\hline $\begin{array}{l}\text { (6)Policy trust } \\
\text { trust }\end{array}$ & $0.213^{* * *}$ & -0.087 & 0.000 & $0.254^{* * *}$ & 0.000 & 1 & & & & \\
\hline (7)Official trust & $0.157^{* *}$ & $-0.140^{*}$ & -0.018 & 0.083 & 0.000 & 0.000 & 1 & & & \\
\hline $\begin{array}{l}\text { (8)Administrative } \\
\text { performance }\end{array}$ & $0.156^{* *}$ & $0.165^{* *}$ & -0.062 & $0.183^{* *}$ & $0.174^{* *}$ & $0.289^{* * * *}$ & $0.199^{* * *}$ & 1 & & \\
\hline $\begin{array}{l}\text { (9)Economic } \\
\text { performance }\end{array}$ & $0.241^{* * *}$ & $-0.129^{*}$ & -0.009 & 0.102 & -0.008 & $0.421^{* * *}$ & $0.197^{* *}$ & 0.000 & 1 & \\
\hline $\begin{array}{l}\text { (10)Social } \\
\text { performance }\end{array}$ & 0.031 & $-0.142^{*}$ & 0.033 & $0.137^{*}$ & $0.148^{*}$ & $0.361^{* * *}$ & -0.109 & 0.000 & 0.000 & 1 \\
\hline
\end{tabular}

IV. EMPIRICAL RESULTS AND ANALYSIS

In order to eliminate the multi-collinearity that may exist between variables, the study generates a new variable for 
each principal component of political trust and execution performance, and uses this as the basic data to verify the hypothesis relationships.

A. Policy Implementation and Government Trust Data Analysis

In order to verify the relationship between the performance of the policy and the governmentundefineds trust, the study conducted a hierarchical regression analysis according to the following steps: firstly, the control variables such as sex, age, education, position and the like are included in the model to control the influence of the mixing factors, so that the model 1 in Table 2 is obtained; The second step, on the basis of the first step, takes administrative performance, social performance and economic performance as independent variables, and takes the government trust as the dependent variable, so that the model 2 in Table 2 is obtained.

From the model 2 in Table 2, it can be seen that in the case of controlling gender, age, education, position and other variables, administrative performance, social performance and economic performance have not shown a significant positive impact on government trust, thus Negated H1(a, b, c). A possible explanation for this result is that there may be other more complicated mechanisms of action between variables such as administrative performance, social performance and economic performance and government trust. There may be adjustment variables or indirect variables between the two. Of course, this idea needs to be verified.

TABLE II Policy Execution and Government Trust Relationship Test

\begin{tabular}{|l|l|l|}
\hline variable & \multicolumn{2}{|l|}{$\begin{array}{l}\text { Dependent variable } \\
\text { (Government trust })\end{array}$} \\
\hline Control variable & Model1 & Model2 \\
\hline Gender & 0.001 & -0.009 \\
\hline Age & $-0.161^{*}$ & $-0.132^{*}$ \\
\hline Education & -0.117 & -0.108 \\
\hline Position & -0.009 & -0.04 \\
\hline Independent variable & & $0.154 *$ \\
\hline Administrative & & -0.02 \\
\hline Economic performance & & $-0.139 *$ \\
\hline Social performance & & 0.073 \\
\hline $\mathrm{R}^{2}$ & 0.033 & 0.031 \\
\hline Adjusted $\mathrm{R}^{2}$ & 0.008 & 1.735 \\
\hline F-value & 1.323 & \\
\hline
\end{tabular}

Note : * means $\mathrm{p}<0.1$ :**means $\mathrm{p}<0.05 ; * * *$ means $\mathrm{p}<0.001$

\section{B. Policy Implementation and Policy Trust Data Analysis}

Similarly, in order to verify the hypothesis of policy implementation and policy trust relationship, the study conducts hierarchical regression analysis according to the above steps: First, the control variables such as gender, age, education, and position are included in the model, and the model 3 of Table 3 is obtained; In the second step, on the basis of the first step, the government trust, policy trust, and official trust are the independent variables, and the economic performance is the dependent variable, so the model 4 in Table 3 is obtained.

From the model 4 in Table 3 , it can be seen that in the case of controlling gender, age, education, position and other variables, political performance, administrative performance and social performance have a significant positive impact on policy trust, thus verifying $\mathrm{H} 2(\mathrm{a}, \mathrm{b}, \mathrm{c})$. This shows that policy implementation has a great impact on the public's policy trust, and the government can change the public's trust in policy by improving policy implementation performance. The government has provided a direction to improve policy trust.

TABLE III Policy Implementation and Policy Trust Relationship Test

\begin{tabular}{|l|l|l|}
\hline variable & \multicolumn{2}{|l|}{$\begin{array}{l}\text { Dependent variable } \\
\text { (Policy trust })\end{array}$} \\
\hline Control variable & Model3 & Model4 \\
\hline Gender & $0.175^{*}$ & 0.061 \\
\hline Age & 0.056 & 0.150 \\
\hline Education & 0.012 & 0.035 \\
\hline Position & $0.241^{*}$ & 0.163 \\
\hline Independent variable & & \\
\hline Administrative performance & \multicolumn{2}{|l}{} \\
\hline Economic performance & & $0.277^{* * *}$ \\
\hline Social performance & & $0.409^{* * *}$ \\
\hline $\mathrm{R}^{2}$ & 0.094 & $0.357^{* * *}$ \\
\hline Adjusted $\mathrm{R}^{2}$ & 0.071 & 0.422 \\
\hline F-value & $4.063^{* *}$ & 0.396 \\
\hline
\end{tabular}

Note: * means $\mathrm{p}<0.1$ :**means $\mathrm{p}<0.05 ; * * *$ means $\mathrm{p}<0.001$

C. Policy Implementation and Official Trust Data Analysis

Similarly, to verify the relationship between policy performance and government trust, the study follows the following steps for hierarchical regression analysis: The first step is to incorporate control variables such as gender, age, education, and position into the model to control the effects of mixed factors. The model 5 in Table 4 is obtained; the second step is based on the first step, with administrative performance, social performance and economic performance as independent variables, and government trust as the dependent variable, thus obtaining the model 6 in Table 4 
From the model 6 in Table 4, it can be seen that in the case of controlling gender, age, education, position and other variables, administrative performance, social performance and economic performance have not shown a significant positive impact on government trust, thus Denied H3(a, b, c). A possible explanation for this result is that too low policy implementation efficiency may not be able to exert its significant impact on official trust. In particular, the corruption that has been exposed in China is not only not conducive to the government's implementation of the governance functions given to it by the public, but will also greatly reduce the degree of trust of policy audiences to government officials, thus having a major impact on a country's economic and social development.

TABLE IV Policy Execution and Official Trust Relationship Test

\begin{tabular}{|c|c|c|}
\hline variable & \multicolumn{2}{|c|}{$\begin{array}{l}\text { Dependent variable } \\
\text { (Official trust) }\end{array}$} \\
\hline Control variable & Model5 & Model6 \\
\hline Gender & 0.130 & 0.073 \\
\hline Age & -0.111 & -0.094 \\
\hline Education & -0.036 & -0.017 \\
\hline Position & 0.009 & -0.003 \\
\hline \multicolumn{3}{|l|}{ Independent variable } \\
\hline Administrative performance & & $0.172 *$ \\
\hline Economic performance & & $0.168^{*}$ \\
\hline Social performance & & $-0.124 *$ \\
\hline$\overline{\mathrm{R}^{2}}$ & 0.037 & 0.106 \\
\hline AdjustedR $^{2}$ & 0.013 & 0.065 \\
\hline F-value & 1.524 & 2.595 \\
\hline
\end{tabular}

\section{CONCLUSION AND DISCUSSION}

\section{A. Analysis Conclusion}

In order to effectively alleviate the problem of public political trust, the study uses behavioral theory to explore the micro-psychological perspective of the political trust of policyexecuting audiences, systematically proposes the relationship between political trust and policy implementation, and based on 162 valid sample data pairs. The hypothesis was verified and the following conclusions were reached.

1) Policy implementation has indeed played a significant positive impact on policy trust. More specifically, overall, social performance, administrative performance, and social performance of policy implementation have shown a significant positive impact on policy trust; official trust has shown significant impact on administrative performance and economic performance of policy execution. Positive impact. From the perspective of policy trust dimension, compared with government trust and official trust, policy performance has shown the strongest positive promotion effect on policy performance. By comparing Model 3 and Model 4, we can find that adding independent variables, the performance of policy execution performance on policy trust is significantly more significant. R2 of Table 3 was changed from 0.094 to 0.422 , which was also significantly better than Table 2 and Table 4.

2) Policy implementation has no significant positive and significant impact on government trust and official trust. Not only the normalization coefficients of the individual selfcontained variables have no effect, but the F-value and the R2 value also exhibit an insignificant adjustment effect consistent with the preset direction. Of course, these are subject to further detailed research.

\section{B. Research Inspiration}

1) Strive to improve policy implementation performance. The research results show that the various dimensions of policy performance have a significant positive impact on policy trust. Accordingly, relevant government departments should vigorously improve the level of policy implementation. Specifically, on the one hand, through various traditional and non-traditional media channels, we should vigorously promote supportive policies that are conducive to policy trust, and continue to strengthen the significant positive impact of policy implementation on political trust; on the other hand, government officials should Integrity and self-discipline, refusing corruption, and working hard to improve their work level, thereby activating their significant positive impact on policy trust.

2) Policy implementation performance has no significant positive effect on government trust and official trust. However, their standardization coefficients are significant, which also shows that the addition of independent variables has a certain effect on the model. Although the values of F and R2 of the model are consistent with the preset direction and not significantly adjusted, they still have certain value. Of course, these need to be further detailed research and discussion.

\section{INSUFFICIENT RESEARCH AND FUTURE PROSPECTS}

Due to limited personal ability, this paper still has many shortcomings, mainly in the following aspects: (1) The data of the thesis is limited in scope, and the age of the subjects is mainly concentrated between $20-40$ years old. The education level is relatively good, and the subjects are involved. The scope of work is relatively limited, and the effective sample of the overall data is less than 200 copies, which is not universal. Subsequent work will be expanded in these areas with targeted supplements. (2) The model established by the author is relatively simple, and there are no important variables such as indirect variables and adjustment variables. It is a bit weak in sorting out the working mechanism of summing up political trust and policy implementation performance. The next step will focus on the key role of regulatory variables and indirect variables, and further explore the direction and relationship between the two. (3) When discussing the interaction between 
political trust and policy implementation performance, the author made a prior assumption. In the following work process, we will further explore the working relationship between political trust and policy implementation performance.

\section{ACKNOWLEDGMENT}

This work was supported by regional project of national natural science foundation of China(the project number is 71764033), supported by applied basic research project of Yunnan(the project number is 2017FB101), supported by the graduate innovation fund project of Yunnan University of Finance and Economics (the project number is 2020YUFEYC014). Thank for all the sponsors.

\section{REFERENCES}

[1] Qingyan,Cao, Dongxu.Xiang A Review of Current Research on Domestic Political Trust $[\mathrm{J}]$. Journal of Social Sciences of Shanxi Colleges, 2018, 30(11): 27-30.

[2] Jiayu.Chen Exploration and Reflection on Issues Related to Political Trust[J]. Journal of Southeast University, 2012, 14(6): 40-41.

[3] Blind, P. K. Building Trust in government in the Twenty-first century: Review of literature and emerging issues[C]. 7th Global Forum on Reinventing Government Building Trust in Government, 2007: 26-29.

[4] Tangbiao,Xiao Xin.Wang The Change of Chinese Peasants' Political Trust--A Tracking Study of 60 Villages in Five Provinces (1999 2008)[J].Management World,2010,26(9):88-94.
[5] Wang, Z. X. Political trust in China: Forms and causes[J]. Legitimacy: Ambiguities of Political Success or Failure in East and Southeast Asia, 2005, 113-139.

[6] Wei Zhang, Wang Erping. The Influence of Political Trust on Public Attitudes and Cooperative Behaviors in Social Distress[J]. Advances in Psychological Science, 2010, 18(10): 1620-1627.

[7] Chunfu Wang. Implementation Mechanism of Policy Network and Public Policy Effectiveness[J]. Management World, 2006(9).

[8] Meijuan Xiong. Theoretical Summary of Political Trust Research[J]. Public Administration Review, 2010(6).

[9] Zhuangrui Zhu, Lü Ping. Regional Differences in the Effectiveness of Urban Land Saving and Intensive Use Policies in China-Analysis and Suggestions Based on Questionnaires of 105 Urban Land Price Monitoring Points in China[J]. China Population, Resources and Environment, 2015, 25(12) : 129-137.

[10] Lirun Mei, Tao Jianwu. Empirical Study of Chinese Political Trust: Panoramic Review and Future Prospects [J]. Socialist Studies, 2018, 41(3): 162-172.

[11] Tangbiao Xiao, Xin Wang. The Change of Chinese Farmers' Political Trust--A Tracking Study of 60 Villages in Five Provinces (1999 2008)[J]. Management World, 2010, 26(9): 90-94.

[12] Rozin,P.,Royzman,E.B.Negativitybias, negativity dominance, and contagion[J].Personalityand Social Psychology Review, 2001, 5(4): 296320 .

[13] Spoor, J. R. Mood convergence in dyads: Effects of valence and leadership[J]. Social Influence, 2009, 4(4): 282-297.

[14] Schoon, I., Cheng, H., Gale, C. R., Batty, G. D., Deary, I. J. Social status, cognitive ability, and educational attainment as predictors of liberal social attitudes and political trust[J].Intelligence, 2010, 38(1): 144-150.

[15] Serek, J., Macek, P. Antecedents of political trust in adolescence: Cognitive abilities and perceptions of parents [J]. Journal of Applied Developmental Psychology, 2014, 35(4): 284-293 